\title{
PENGARUH GAYA KEPEMIMPINAN TERHADAP KEPUASAN KERJA KELURAHAN SERUA INDAH, TANGERANG SELATAN
}

\author{
Krisnaldy .SE.M.S.i \\ Staf Pengajar Fakultas Ekonomi Universitas Pamulang \\ Email: $\underline{\text { dosen01890@unpam.ac.id }}$
}

\begin{abstract}
ABSTRAK
Penelitian ini memiliki tujuan untuk mengetahui pengaruh antara gaya kepemimpinan terhadap kepuasan kerja di Kelurahan Serua Indah, Tangerang Selatan, untuk mengetahui pengaruh secara parsial antara terhadap kepuasan kerja di Kelurahan Serua Indah, Tangerang Selatan dan untuk mengetahui pengaruh secara simultan antara gaya kepemimpinan dan terhadap kepuasan kerja di Kelurahan Serua Indah, Tangerang Selatan. Data yang digunakan dalam penelitian ini menggunakan data primer yang diperoleh dari jawaban dari responden yang menjadi pegawai di Kelurahan Serua Indah, Tangerang Selatan yang diberikan kuesioner. Pemilihan sampel dilakukan dengan menggunakan rumus slovin. Hasil penelitian ini menunjukkan bahwa terdapat pengaruh secara simultan pada variabel gaya kepemimpinan, dan terhadap kepuasan kerja. Hasil penelitian ini juga menunjukkan variabel gaya kepemimpinan, dan berpengaruh signifikan secara parsial terhadap kepuasan kerja. Pada koefisien determinasi terdapat pengaruh sebesar $81,1 \%$ yang mempengaruhi kepuasan kerja yang dijelaskan oleh variabel gaya kepemimpinan, dan , sedangkan sisanya 18,9\% dipengaruhi oleh variabel lain dan tidak termasuk kedalam analisis regresi ini.
\end{abstract}

Kata kunci: gaya kepemimpinan,, kepuasan kerja

\begin{abstract}
This research aims to know the influence of partially between leadership style towards job satisfaction in the offices of Large Hall area 2 kelurahan serua indah Ciputat, to know the influence of partially between motivation work towards job satisfaction in The kelurahan serua indah Ciputat and to know the influence of simultaneously between leadership style and motivation work towards job satisfaction in the kelurahan serua indah Ciputat. The data used in this research using primary data obtained from answers from respondents The results of this research show that there are simultaneous influence on the variable style of leadership, work motivation and job satisfaction toward the work environment. The results of this research also indicates the variable style of leadership, and towards job satisfaction. On the coefficient of determination there are $81.1 \%$ of influence that affect job satisfaction variable explained by the leadership styles, motivation of work and work environment, while the remaining $18.9 \%$ is affected by other variables and does not include into this regression analysis.
\end{abstract}

Keywords: leadership styles, job satisfaction

\section{PENDAHULUAN}

\section{A. Latar Belakang}

Karyawan merupakan salah satu aset syarikat penting dan perlu diuruskan dan dibangunkan untuk menyokong kelangsungan hidup syarikat. Syarikat ini juga menghadapi cabaran besar untuk 
@ Prodi Manajemen Fakultas Ekonomi Universitas Pamulang

memenangi pertandingan, begitu juga taktik dan strategi yang tepat. Dalam memilih taktik dan strategi, syarikat bukan sahaja memerlukan analisis perubahan dalam persekitaran luaran seperti demografi, sosio-kebudayaan, politik, teknologi dan persaingan, tetapi juga perlu menganalisis faktor dalaman syarikat. Faktor dalaman yang dipersoalkan adalah kekuatan dan kelemahan syarikat dalam usaha untuk menyokong dan mencapai sasaran yang ditetapkan. Faktor internal akan menyebabkan semakin buruknya kondisi perusahaan karena adanya perbedaan sikap, perasaan, pikiran dan karakteristik setiap pegawai (Ardana, 2012:17).

Manajemen sumber daya manusia merupakan proses mengenal pasti, menggalakkan, mengukur, menilai, meningkatkan dan memberi ganjaran prestasi pekerja. Definisi lain dinyatakan oleh Dessler (2005) dalam Riani (2013: 63) yang menyatakan bahawa pengurusan sumber manusia adalah proses yang menyatukan penetapan tujuan, penilaian prestasi dan pembangunan satu sistem yang bertujuan untuk memastikan prestasi pekerja menyokong dan sesuai dengan tujuan perusahaan.

Salah satu organisasi yang membutuhkan manajemen sumber daya manusia adalah instansi di kelurahan serua Hal ini dikarenakan instansi ini merupakan unit pelaksanaan teknis yang salah satu tugas pokoknya memberikan pelayanan kepada masyarakat.

Pekerja yang mendapat kepuasan kerja akan melakukan pekerjaan mereka dengan lebih baik, pekerja yang tidak mendapat kepuasan kerja tidak akan mencapai kematangan psikologi yang akan menyebabkan kekecewaan. Pekerja seperti ini selalunya meratap, semangat yang rendah, cepat bosan dan letih, emosi yang tidak stabil, sering tidak hadir dan sibuk melakukan apa-apa kaitan dengan kerja yang mesti dilakukan (Hasibuan, 2012: 32). Kepuasan tinggi akan membawa kepada tahap rendah dan ketidakhadiran yang rendah kerana individu yang berpuas hati digalakkan untuk bekerja dengan lebih baik kerana pentingnya berpuas hati. Apabila seorang pekerja merasa puas dalam kerja maka seorang pekerja akan berusaha untuk menyelesaikan tugasnya, yang pada akhirnya akan menghasilkan kualiti perkhidmatan yang tinggi dan pencapaian tujuan syarikat.

Gaya kepimpinan adalah salah satu faktor yang boleh mempengaruhi prestasi pekerja. Pendapat penulis ini sejalan dengan pendapat Ardana (2012:181) yang menyatakan bahwa kepemimpinan suatu organisasi akan mempengaruhi bawahannya, maka dengan kepemimpinan yang baik akan mempengaruhi kinerja yang baik pula. 
@ Prodi Manajemen Fakultas Ekonomi Universitas Pamulang

Setiaap peemimpin paada daasarnya mempunyai tingkah laku yang berbeza dalaam memmimpin penngikutnya, tingkah laku pemmimpin dipanggil gaya kepimpinan. Kepimpinan memiliki hubungan yang sangat dekat dengan motivasi, kerana kejayaan seorang pemimpin dalam memindahkan orang lain dalam mencapai matlamat yang dimaksudkan sangat tergantung pada otoritas, dan juga pemimpin dalam menciptakan motivasi di dalam setiap subordinat, kolega dan pemimpin bos itu sendiri.

Kurangnya peranan kepimpinan dalam mewujudkan komunikasi harmoni dan menyediakan panduan pekerja akan membawa kepada tahap prestasi pekerja yang rendah. Begitu juga dengan kurangnya motivasi pekerja seperti tidak disiplin dalam kerja, kemalasan dalam kerja akan menyebabkan prestasi pekerja yang rendah. Setiap pemimpin pada dasarnya mempunyai tingkah laku yang berbeza dalam memimpin pengikutnya, tingkah laku pemimpin dipanggil gaya kepimpinan. Kepimpinan mempunyai hubungan yang sangat dekat dengan motivasi, kerana kejayaan seorang pemimpin dalam memindahkan orang lain dalam mencapai matlamat yang dimaksudkan sangat tergantung pada otoritas, dan juga pemimpin dalam menciptakan motivasi dalam setiap bawahan, kolega dan pemimpin bos itu sendiri.
Faktor motivator berkaitan dengan kerja yang menawarkan pencapaian, pengiktirafan, kerja yang mencabar, tanggungjawab dan prospek untuk kemajuan. Walaupun faktor kebersihan berkaitan dengan dasar syarikat, pengawasan, gaji, hubungan kerja dan keadaan kerja. Kesimpulannya, faktor kebersihan hanya dapat menghapuskan ketidakpuasan, tidak dapat meningkatkan kepuasan kerja, sementara faktor motivator dapat meningkatkan kepuasan kerja jika faktor ini ada.

Faktor lain yang mampu memberikan kepuasan bagi karyawan adalah , menurut Hemsath dan Yerkes (2006:2) yang menyenangkan berpengaruh positif pada produktivitas, kualitas, pelayanan konsumen dan kepuasan kerja. yang kondusif memungkinkan karyawan lebih bersemangat dalam bekerja. yang baik, bersih akan memotivasi karyawan dalam melakukan pekerjaan dengan baik. Dengan memperhatikan yang baik menciptakan kondisi kerja yang mampu memberikan motivasi untuk bekerja (Isminar, 2015:124).

\section{B. Rumusan Penelitian}

Kepuasan kerja memiliki banyak faktor yang mempengaruhinya untuk mengetahuinya diperlukan analisa yang berdasarkan teori, maka rumusan penelitian permasalahan yang akan diteliti antara lain:

1. Apakah terdapat Pengaruh gaya 


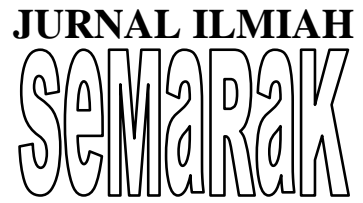

kepemimpinan ?

2. Apakah terdapat pengaruh secara gaya kepemimpinan terhadap kepuasan kerja di Kelurahan Serua Indah, Tangerang Selatan ?

\section{Tujuan Penelitian}

Berdasarkan latar belakang masalah dan perumusan masalah, maka tujuan dalam penelitian ini adalah sebagai berikut:

1. Unntuk mengetahui peengaruh seecara satu persatu antara gaya kepemimpinan teerhadap kepuuasan keerja di Kelurahan Serua Indah, Tangerang Selatan.

2. Untuk mengetahui pengaruh serentak antara gaya kepimpinan dan terhadap kepuasan kerja di Kelurahan Serua Indah, Tangerang Selatan.

\section{TINJAUAN PUSTAKA}

\section{A. Manajemen Sumber Daya Manusia}

\section{Pengertian Manajemen}

"Manajemen berasal dari kata untuk mengelola, yang berarti mengelola, mengelola, mengelola, melaksanakan, dan mengendalikan. Manajemen adalah ilmu dan seni yang mengatur proses pemanfaatan sumber daya manusia dan sumber lain secara efektif dan efisien untuk mencapai tujuan tertentu" (Ardana, 2012:4).

Menurut Kasmir, "manajemen mengelola atau mengelola suatu kegiatan. Dalam arti sempit dikatakan bahwa manajemen mengelola perusahaan untuk mencapai tujuan melalui orang lain. Yang diatur dan dikelola adalah aset atau aset perusahaan, baik properti manusia, peralatan mesin, proses dan prosedur kerja. Aset ini perlu dikelola dengan baik, terus menerus dan berkesinambungan, jika Anda ingin menghasilkan hasil yang optimal seperti yang diharapkan" (Kasmir, 2016:10).

Menurut Lee dalam Swastha dan Sukotjo (2010:82) manajemen adalah ilmu dan seni merencanakan, mengorganisasi, mengarahkan, mengkoordinasikan serta mengawasi tenaga manusia dengan bantuan alatalat unntuk meencapai tuujuan yaang tellah dittetapkan. Darri defiinisi maanajemen tersebut dapat diambil suatu kesimpulan bahwa manajemen mempunyai lima fungsi, yaitu (proses perencanaan, proses pengorganisasian, pengarahan, pengkoordinasian dan pengawasan.

Kelima macam fungsi manajemen ini sangat penting di dalam menjalankan semua kegiatan. Semua ini dimaksudkan agar kegiatan apapun yang dilakukan dapat berjalan baik, sehiingga tuujuan yaang teelah diteetapkan dappat teercapai. Setiiap kegiiatan yaang dilakukan oleh seseorang atau sebuah lembaga tentu 
Jurnal Semarak,Vol. 3,No.1, Februari 2020, Hal (111- 122)

@ Prodi Manajemen Fakultas Ekonomi Universitas Pamulang

memiliki tujuan dan untuk mecapai tujuan perlu adanya perencanaan yang menggambarkan

1) Apa,

Bagaimana, 3) Mengapa dan 4) Kapan akan dilakukan (Swastha dan Sukotjo, 2010:82).

\section{Pengertian Sumber Daya Manusia}

Mengelola sumber daya manusia harus dilakukan secara benar sesuai dengan kaidah-kaidah kmanusiaan atau kodratnya. Jika di zaman dahulu manusia atau karyawan dianggap sebagai mesin yang dapat dilakukan dengan semena-mena demi mencapai tujuan perusahaan. Manusia dianggap sebagai budak yang dapat diperintah semaunya. Namun saat ini sesuai dengan perkembangannya, manusia semakin diperhatikan bahkan sekarang sudah berubah menjadi asset yang paling penting untuk diperhatikan (Kasmir, 2016:5).

Salah satu sumber organisasi yang mempunyai peranan penting dalam mencapai objektifnya adalah sumber manusia. Oleh karena pentingnya peran manusia dalam kompetisi baik jangka pendek maupun jangka panjang dalam agenda bisnis, suatu organisasi harus memiliki nilai lebih dibandingkan dengan organisasi lainnya. Organisasi yang berhasil dalam mempengaruhi pasar jika dapat menarik perhatian atas kelebihan yang dimiliki dalam berbagai hal dibandingkan dengan organisasi lain (Bangun, 2012:4).

Sutrisno (2016:3) mengatakan bahwa summber daaya maanusia meruupakan saatu-satunya sumber daya yang memiliki akal perasaan, keinginan, keterampilan, pengetahuan, dorongan, daya dan karya (rasio, rasa dan karsa). Semua potensi sumber daya manusia tersebut berpengaruh terhadap upaya organisasi dalam mencapai suatu tujuan.

3. Pengertian Manajemen Sumber Daya Manusia

Manajemen Sumber Daya Manusia adalah proses pengelolaan manusia, melalui perencanaan, rekrutmen, seleksi, pelatihan, pengembangan, pemberian kompensasi, karier, keselamatan dan kesehatan serta menjaga hubungan industrial sampai pemutusan hubungan kerja guna mencapai tujuan perusahaan dan peningkatan kesejahteraan stakeholder. Pengertian manajemen sumber daya manusia dari beberapa ahli MSDM: Noe menyebutkan Human Resources Management refers to Policies, practices and systems that influenza employees' behavior, attitudes, and performance (manajemen sumber daya manusia merupakan bagaiman mempengaruhi perilaku, sikap dan kinerja melalui kebijakan dan sistem yang dimiliki 
Jurnal Semarak,Vol. 3,No.1, Februari 2020, Hal (111- 122)

@Prodi Manajemen Fakultas Ekonomi Universitas Pamulang

oleh perusahaan. Menurut Dessler

Human Resources Management is the process of acquiring, training, appraising and compensating employees, and attending their labor relations, health and safety, and fairness concern (manajemen sumber daya manusia merupakan proses mengendalikan latihan penilaian pekerja, pampasan, kesihatan dan keselamatan pekerjaan dengan adil kepada fungsi MSDM.

Pengertian manajemeen summber daya manuusia addalah suatu kegiatan yang meliputi proses perencanaan, proses pengorganisasian, penyusunan personalia, penggerakan dan pengawasan terhadap fungsi-fungsi operasionalnya untuk mencapai tujuan perusahaan (Bangun, 2012:5).

Berdasarkan pengertian di atas maka dapat disimpulkan pengertian Mannajemen Summber Daaya Mannusia addalah segalah kegiatan dengan menggerakan summber dayya manuusia yang ada untuk mencapai tujuan perusahaan.

\section{B. Gaya Kepemimpinan}

Pemmimpin merrupakan seseeorang yanng memiiliki kemmampuan memmimpin arrtinya memmiliki kemaampuan unntuk mempengaruhi prilaku orang lain (Thoha, 1983) dalam (Ardana, dkk, 2012:179). Sedangkan kepemimpinan merupakan seluruh aktivitas dalam rangka mempengaruhi orang-orang agar mau bekerja sama mencapai suatu tujuan yang memang diinginkan bersama (Martoyo, 1990) dalam (Ardana, dkk, 2012:179).

Kepemimpinan (Leadership) adalah proses pengaruh sosial, yaitu suatu kehidupan yang mempengaruhi kehidupan lain, kekuatan yang mempengaruhi perilaku orang lain ke arah pencapaian tujuan tertentu (Soekarso dan Putong, 2015:9). Sedangkan pemimpin (Headship) adalah orang-orang yang memimpin atau para pemimpin (Supranto, 2007:24).

Berdasarkan pengertian para ahli di attas makaa dappat disimpullkan yaang dimaksud dengan kepemimpinan adalah suatu kemampuan yang dapat mempengaruhi dan menggerakkan orang lain dalam rangka mencapai suatu tujuan yang diinginkan bersama. Sedangkan yang dimaksud dengan pemimpin adalah seseorang yang mampu menggerakkan orang lain agar mau bekerja sehingga mencapai suatu tujuan bersama.

\section{Kepuasan Kerja}

Keepuasan keerja adaalah konnsep yaang mempunyai banyak dimensi, bermakna kepuasan kerja dipengaruhi oleh berbagai factor. Kepuasan kerja mempunyai banyak dimensi. Secara umum, tahap yang diperhatikan adalah kepuasan kerja itu sendiri, gaji, pengiktirafan, hubungan antara penyelia dan buruh, dan peluang untuk maju. Setiap 
Jurnal Semarak,Vol. 3,No.1, Februari 2020, Hal (111- 122)

@Prodi Manajemen Fakultas Ekonomi Universitas Pamulang

dimensi menghasilkan perasaan kepuasan secara keseluruhan dengan kerja itu sendiri, tetapi kerja juga mempunyai definisi yang berbeza untuk orang lain. Kebutuhan-kebutuhan pegawai tidak saja menyangkut kebutuhan yang bersifat fisik, akan tetapi kebutuhan sosial, keamanan, jaminan-jaminan pegawai dan perlindungan. Kebutuhan lain yang menyangkut pegawai, kadang-kadang terkait dengan persoalan kebosanan atas rutinitas yang terjadi, sehingga pegawai membutuhkan sistem rotasi kerja (Rosidah, 2009:301).

Ini juga dinyatakan oleh Sunyoto (2012:26), bahawa kepuasan kerja (kepuasan kerja) adalah keadaan emosi yang menyenangkan atau tidak menyenangkan di mana pekerja memandang kerja mereka. Perasaan ketidakpuasan kerja pekerja timbul apabila jangkaan mereka tidak dipenuhi. Secara formal, kepuasan kerja adalah tahap syarikat seseorang untuk pekerjaannya.

Untuk mengetahui betapa memuaskannya keperluan pekerja, pasukan audit mengumpul data daripada pekerja yang berkaitan dengan gaji, faedah, amalan penyeliaan, bantuan perancangan kerjaya dan maklum balas yang diterima oleh pekerja sebagai kaunter prestasi prestasi. Berdasarkan maklumat dan data, pasukan audit boleh menganalisis tahap kebajikan pekerja dan tahap kepuasan pekerja (Rosidah, 2009:302).

\section{Hipotesis Penelitian}

Menurut rangka kerja di atas selaras dengan objektif kajian untuk menjawab soalan penyelidikan, hipotesis yang diuji adalah seperti berikut:

1. $\mathrm{H}_{\mathrm{o}}$ : tidak memiliki pengaruh secara parsial (satu per satu) antara variabel gaya kepemimpinan terhadap kepuasan kerja.

$\mathrm{H}_{\mathrm{a}}$ : memiliki pengaruh secara parsial (satu per satu) antara variabel antara gaya kepemimpinan terhadap kepuasan kerja karyawan.

\section{METODDE PEENELITIAN}

Objek yang digunakan dalam penelitian ini adalah Kelurahan serua Indah. Kaedah yang digunakan dalam kajian ini adalah kaedah kajian kes yang merupakan satu kajian deskriptif, dengan kajian ini dijangka akan mendedahkan secara mendalam pembolehubah yang akan dapat menggambarkan analisis pengaruh gaya kepemimmpinan dan terhadap kepuasan kerja.

Data yang digunakan menggunakan data primer dan data sekunder. Data primer dalam bentuk wawancara berganda dan dalam bentuk soal selidik sementara data sekunder dalam bentuk benda umum benda penyelidikan

Teknik pensampelan yang akan diambil dalam kajian ini adalah kemudahan pensampelan, yang merupakan istilah umum yang merangkumi pelbagai prosedur untuk memilih responden. Pensampelan 
kemudahan bermaksud unit sampel yang diambil mudah untuk dihubungi, tidak menyusahkan, mudah diukur, dan koperasi. Bagi saiz sampel penyelidikan mengikut Roscoe dalam kaedah penyelidikan buku untuk perniagaan (Sugiyono, 2010:52) menyatakan bahawa saiz sampel yang boleh dilaksanakan dalam kajian adalah antara 30 dan 500. Dalam kajian ini, penyelidik menggunakan sampel sebanyak 71 responden.

Sampel yang diambil dalam penelitian ini adalah sebanyak 71 orang responden yang merupakan karyawan pada Kelurahan serua Indah. Menurut Umar (2005: 53) untuk mengetahui saiz sampel, formula Slovin digunakan dengan peratusan elaun 5\%, iaitu:

$$
\mathrm{n}=\frac{\mathrm{N}}{1+\mathrm{Ne}^{2}}
$$

Dimana:

$\mathrm{n}$ : Ukkuran saampel

$\mathrm{N}$ : Ukkuran poppulasi

e : Perrsentasi keelonggaran

Berdasarkan formula yang dinyatakan di atas, berikut adalah pengiraan sampel penyelidikan seperti berikut:

$$
\begin{aligned}
& \mathrm{n}=\frac{86}{1+86\left(0,05^{2}\right)} \\
& \mathrm{n}=\frac{86}{1,215}=71 \text { Karyawan }
\end{aligned}
$$

Teknik pengumpulan data menggunakan temubual dan pemerhatian dan soal selidik. Sampel yang digunakan sebagai objek kajian ialah 71 pegawai.

\section{HASIIL DDAN PEMMBAHASAN}

\section{A. Gambaran Umuum Kelurahan}

Kelurahan Serua Indah, Kecamatan Ciputat Kota Tangerang Selatan merupakan penghasil tali tambang dan sudah sejak puluhan tahun tali tambang yang di produksi tersebut selalu menjadi andalan para pelaut di Pelabuhan tanjung Priuk, Jakarta.

Kelurahan Serua Indah merupakan hasil pemekaran dari Kelurahan Seru yang terjadi pada Tahun 1984. Asal usul kata 'serua' berasal dari kata 'Sarua' yang dalam bahasa Sunda artinya sama. Sedangkan para sesepuh didaerah tersebut mengenal serua dengan arti wangi atau sama.

Warga serua ini dikenal sebagai pengrajin tali tambang yang dibuat dari karung goni dan hampir setiap rumah banyak terdapat anyaman tali tambang. Produksi tali - tali tambang tersebut kemudian didistribusikan kebeberapa kota di Indonesia.

Dan para pelaut atau kuli bongkar muat di pelabuhan tanjung Priuk disebut - sebut selalu mengandalkan produksi tali tambang dari Kelurahan Serua Indah ini hingga turun temurun.

Selain terkenal sebagai daerah penghasil tali tambang, Kelurahan Serua Indah juga memiliki warisan sejarah wayang yang hingga kini dikenal seantero Tangerang. Hiburan wayang tersebut kerap kali dipentaskan saat ada hajatan warga. Dalangnya sudah keturunan beberapa kali dan itu menjadi warisan yang harus dilestarikan dan nama paguyuban wayang tersebut adalah Lingkung Seni Cinta kasih.

Namun seiring perkembangan, warga kelurahan Serua Indah semakin bertambah penduduknya, sehingga ladang dan sawah 
@ Prodi Manajemen Fakultas Ekonomi Universitas Pamulang

sudah mulai langka. Profesi masyarakatnya sudah mulai bergeser dengan perdagangan dan jasa.

\section{B. Penemmuan dan Pembbahasan}

\section{Hasil Ujji Valliditas}

Kesahan didefinisikan sebagai sejauh mana ketepatan dan ketepatan alat pengukur dalam melaksanakan fungsi saiznya. Memahami kesahihan alat ukur bergantung kepada keupayaan alat untuk mengukur objek yang diukur dengan teliti dan tepat. Keputusan pada item soalan mungkin dianggap sah.

Ujian kesahan dilakukan dengan membandingkan nilai $r_{\text {itung }}$ dengan $r_{\text {tabel }}$, dengan membandingkan nilai $\mathrm{r}_{\text {hitungan }}$ dari output (Corrected Item-Total Correlation) dengan $\mathrm{r}_{\text {table }}$, jika bilangan r lebih besar daripada rtable maka item soalan sah, tetapi jika $r_{\text {hitung }}$ lebih kecil dari pada $r_{\text {tabel }}$ maka butir pertanyaan tersebut tidak valid (Ghozali, 2011:54). Ditemukan nilai $r_{\text {tabel }}$ sebesar 0,235. Didapat dari jumlah kasus - 2, atau 71 $2=69$, tingkat signifikansi 5\%, maka didapat $r_{\text {tabel }} 0,235$. Berikut ini adalah hasil uji validitas pada variabel penelitian (gaya kepemimpinan, dan kepuasan kerja pegawai):. Tabel 1

\section{Hasil Uji Validitas}

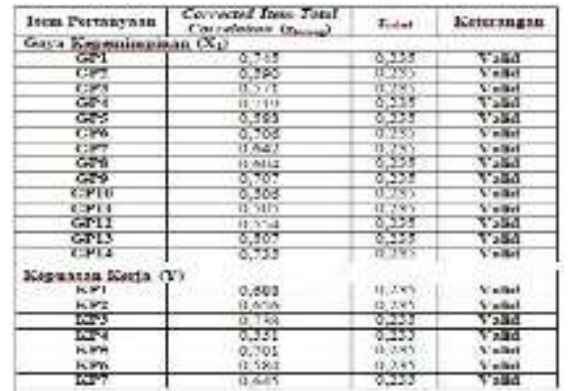

Sumber: Data Diolah

Hasil try out tersebut, diperoleh data yang menyatakan bahwa dari item pertanyaan yang diberikan kepada 98 responden ditemukan nilai Corrected Item-Total Correlation ( $\left.\mathrm{r}_{\text {tabel }}\right)$ lebih besar dari nilai $0,235 \quad\left(\mathrm{r}_{\text {tabel }}\right)$ yang berarti valid maka dapat dilanjutkan ke penelitian berikutnya.

\section{a. Hasiil Koefisieen Persaamaan Ujji} Regresi Liniear sederhana

Analisis regresi linier berganda adalah ujian yang digunakan untuk menentukan berapa banyak pengaruh antara pembolehubah bebas (gaya kepemimpinan, dan ) pada pembolehubah yang bergantung kepada (kepuasan kerja). Hasil pengaruh regresi linier berganda gaya kepemimpinan, dan Mencari Pengubah kepuasan kerja adalah seperti berikut:

Tabel 4

Haasil Koefiisien Perssamaan Reegresi Liinier Beerganda

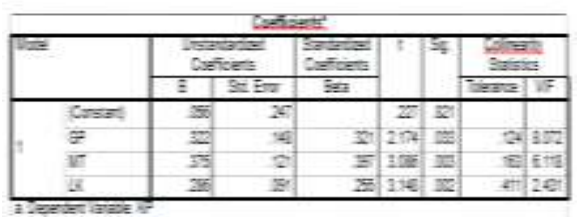

Sumber: Data primer yang diolah 


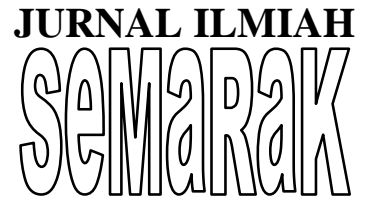

Jadual di atas boleh dirumuskan persamaan regresi untuk menentukan kesan atribut produk, promosi dan pencarian pelbagai

ke arah menaip jenama seperti berikut:

$\mathrm{Y}=\mathrm{a}+\mathrm{bx} 1+\mathrm{bx} 2$

$Y=0,056+0,322 X_{1}+0,375 X_{2}$

Keterangan :

Y : kepuasan kerja

$\mathrm{X} 1$ : gaya kepemimpinan

Koefisien persamaan regresi linear berganda di atas boleh ditafsirkan sebagai pekali regresi malar 0.056 menunjukkan bahawa jika gaya kepemimpinan, dan adalah sifar, nilai kepuasan kerja ialah 0,056 unit atau $5,6 \%$. Perhatikan bahawa pembolehubah lain dianggap malar. Variabel gaya kepemimpinan 0,322 menunjukkan bahawa jika pemboleh ubah gaya kepemimpinan meningkat sebanyak 1 unit, ia akan meningkatkan kepuasan kerja sebanyak 0,322 unit atau $32,2 \%$. Variabel motiivasi keerja 0,375 menunjukkan bahawa jika kenaikan nilai sebesar 1 unit, ia akan meningkatkan sebanyak 0,375 unit atau 37,5\%. variabel 0,286 menunjukkan bahawa jika variasi vaiabel sebanyak 1 unit maka ia akan meningkatkan kepuasan kerja

\section{Hasiil Ujji Hipootesis}

\section{a. Hasisl Uji Sttatistik F}

Ujian $F$ telah dijalankan untuk melihat gayaa keepemimpinan, motiivasi kerja dan secara keseluruhan pada pemboleh ubah beralih jenama. Berikut adalah keputusan ujian serentak, keputusan ujian ANOVA diperolehi seperti berikut:

Tabel 5

Hasil Uji Statistik F (Simultan)

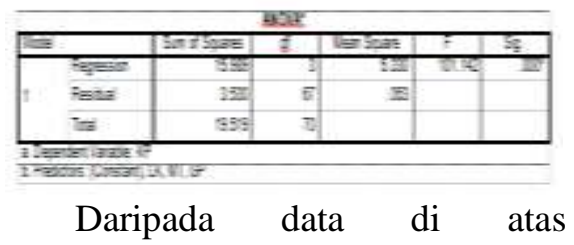

memperoleh nilai signifikan 0,000 bermakna bahawa peruntukan nombor dua terpakai dalam kajian ini yang $\mathrm{H}_{\mathrm{o}}$ ditolak dan $\mathrm{H}_{\mathrm{a}}$ diterima. Keputusan ujian $\mathrm{F}$ ini menyatakan bahawa keputusan ujian serentak di atas adalah benar.

Dalam kajian ini, nilai $\mathrm{F}$ yang dikira adalah 101,142 yang lebih besar daripada nilai $F_{\text {tabel }}$ 2,74. Ini bermakna bahawa peruntukan nomor empat adalah benar. Sebagai kesimpulan, terdapat pengaruh linier antara variabel bebas dan pemboleh ubah yang bergantung.

\section{b. Hasil Ujii t (Ujii Seccara Paarsial)}


Jurnal Semarak,Vol. 3,No.1, Februari 2020, Hal (111- 122)

@Prodi Manajemen Fakultas Ekonomi Universitas Pamulang

Tabel 6

Haasil Ujji t (Ujii Secaara Parsial)

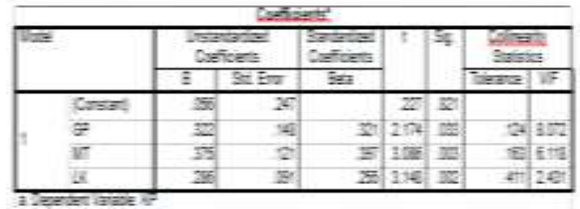

Berdasarkan keputusan ujian $t$, dapat dilihat bahawa semua variable bebas sebahagiannya mempengaruhi kepuasan kerja.

\section{KESIMPULAN DAAN SARAN}

\section{A. Kesimpulan}

Kajian ini dijalankan untuk menentukan kesan gaaya kepeemimpinan, mootivasi keerja dan linggkungan kerja yang dicari pada kepuuasan kerrja. Berdasarkan hasil penyelidikan yang dijelaskan dalam bab sebelumnya, beberapa kesimpulan dapat diambil seperti berikut:

1. Hasil kajian menyatakan bahawa sebahagian atau berdasarkan keputusan ujian $\mathrm{t}$ menunjukkan bahawa variable gaya kepemimpinan berpengaruh terhadap kepuasan kerja.

2. Hasil kajian menyatakan bahawa sebahagian atau berdasarkan keputusan ujian t menunjukkan bahawa variable

\section{Saran}

Hasil kajian inngin meemberikan beeberapa saaran yaang daapat diisampaikan, yiaitu:

1. Sebaiknya Kelurahan Serua Indah, Tangerang Selatan lebih memperbaiki dalam hal meningkatkan gaya kepemimpinan dengan mengawasi kegiatan pegawai agar lebih meningkatkan kepuasan kerja pegawainya

2. Lebih meningkatkan dengan memberikan kompensasi sesuai dengan kebutuhan hidup pegawainya.

3. Sebaiknya Kelurahan Serua Indah, Tangerang Selatan lebih meningkatkan dengan meningkatkan fasilitas dari Kelurahan Serua Indah, Tangerang Selatan.

\section{DAFTAR PUSTAKA}

Ghozali, Imam, "Aplikasi Analisis Multivariat Dengan Program SPSS 19”, Badan Penerbit Universitas Dipenogoro, Semarang, 2011.

Hasibuan, Melayu, "Manajemen Sumber Daya Manusia", PT. Bumi Aksara, Jakarta, 2012.

Rosidah, Ambar Teguh Sulistiyani, "Manajemen Sumber Daya Manusia”, Graha Ilmu, Yogyakarta, 2009.

Sunyoto, Danang, "Sumber Daya Manusia (Praktik Penelitian)", Center For Academic Publishing Service), Yogyakarta, 2012.

Riani, Asri Laksmi, "Manajemen Sumber Daya Manusia, Graha Ilmu, Yogyakarta, 2013..

Hariandja, Marihot Tua Efendi, "Manajemen Sumber Daya Manusia”, Grasindo, Jakarta, 2007.

Sunyoto, Danang, "Sumber Daya Manusia (Praktik Penelitian)", Center For Academic Publishing Service, Yogyakarta, 2012.

Swastha, Bashu, Ibnu Sukotjo, "Pengantar Bisnis”, Liberti, Yogyakarta, 2010 
JURNAL ILMIAH

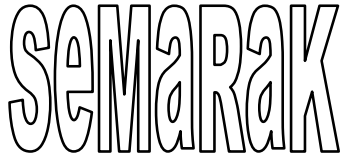

P-ISSN 2615-6849, E-ISSN 2622-3686

Jurnal Semarak,Vol. 3,No.1, Februari 2020, Hal (111- 122)

@Prodi Manajemen Fakultas Ekonomi Universitas Pamulang

Sutrisno Edi, "Manajemen Sumber Daya Manusia”, Kencana, Jakarta, 2016.

Bangun, Wilson, "Manajemen Sumber Daya Manusia”, Erlangga, Jakarta, 2012.

Kasmir, "Manajemen Sumber Daya Manusia (Teori dan Praktik)", PT. Raja Grafindo Persada, Jakarta, 2016.

Krisnaldy, K., Pasaribu, V. L. D., \& Senen, S. (2019). PENGARUH BUDAYA ORGANISASI, LINGKUNGAN KERJA DAN IKLIM ORGANISASI TERHADAP MOTIVASI PEGAWAI SERTA DAMPAKNYA TERHADAP KEPUASAN KERJA. Jurnal Semarak, 2(2).

Pasaribu, V. L. D., Krisnaldy, K., \& Warasto, H. N. (2020). Pengaruh Gaya Kepemimpinan, Disiplin Kerja Dan Kompensasi Terhadap Kinerja Pegawai (Studi kasus kelurahan Pisangan Ciputat). Disrupsi Bisnis, 3(1). 